\title{
Screendance Self/portraits
}

Hetty Blades, Coventry University

\begin{abstract}
Screendance works often comprise multiple authorial perspectives. The camera, staging, sound, choreography and context all contribute to the aesthetic and conceptual potential of the work. This provocation draws on Tamara Tomić-Vajagić's (2014) notion of the 'self-portrait effect' to discuss how a confluence of first and third person perspectives cultivates representations of selfhood in two screendance examples: Vis-er-al (2015) by Polly Hudson and 52 Portraits (2016) by Jonathan Burrows, Matteo Fargion, and Hugo Glendinning.
\end{abstract}

Keywords: self/portrait, screendance, selfhood

The construction and circulation of the self is one of the central features of contemporary culture. Selfies and social media provide ways for us to generate and circulate expressions of ourselves and others, extending the visual art traditions of portraiture and self-portraiture. As Tamara Tomić-Vajagić points out, dance has the potential to problematize the distinction between a portrait and self-portrait due to the interplay between the expression of the choreographer or director and the dancer (in cases where the two are distinct). 1 The aim of this provocation is to raise questions about the way that screendance might further complicate dance's muddling of portraits and self-portraits 2 through the layering of perspectives and the relationship between the body and the camera. I draw on two works: Vis-er-al (2015) by Polly Hudson and 52 Portraits (2016) by Jonathan Burrows, Matteo Fargion, and Hugo Glendinning.

In October 2015, Hudson convened three days of workshops, screenings and performances at Vivid Projects, a collaborative media arts space in Birmingham (UK) as part of their 9 Evenings series, a reference to Billy Klüver's 9 Evenings: Theatre \& Engineering, a collaborative project between artists and scientists in New York in 1966. Hudson's pieces, Vis-er-al (2015) and Making Lemonade (2013) were displayed as installations during the event. Making Lemonade was looped in different times on three screens that surrounded the audience. In another room, Vis-er-al was projected onto a large wall. Both are solo works, choreographed and performed by Hudson. As visitors arrived at the event they were invited to contribute to a "Yes Manifesto," a rethinking of Yvonne Rainer's famous "No Manifesto," 3 adding explanations of what dance might be and granting permissions for its potentiality. On the evening that I 
attended, dance artists Katye Coe and Charlie Morrissey were also part of the event, sharing their joint movement practice in one area of the space.

My next example followed a very different format. Each Monday throughout 2016, a danced vignette arrived in my email inbox, thanks to Burrows, Fargion, Glendinning, and 51 dance artists or partnerships. Each film contains a short 'portrait' of a dance artist or duo, during which they perform a sequence of movements alongside an offscreen vocal accompaniment. Each portrait is situated in the same black-box setting, on or around a chair and table. Each instance is idiosyncratic to the featured artist, yet maintains enough visual uniformity to be clearly part of the same work.

These two works complicate the distinction between portraits and self-portraits. As the title suggests, 52 Portraits is a portrait-like work, however, the work has selfportraiture within it, as each micro-work includes choreography generated by the featured artist. Vis-er-al, on the other hand, is a solo work, based on an autobiographical event. It could therefore be seen as a straightforward self-portrait, but challenges this notion due to the way that the work is edited collaboratively and features multiple viewpoints.

\section{Self/portraits}

The term 'portrait' tends to denote a visual image in which an artist has set out to represent a particular person or group. 4 However, a portrait is not simply a picture of another person. Cynthia Freeland suggests that portraits: must portray a recognizable subject; should reveal something about the inner life of the subject; and require that the person being depicted 'looks back' at, or poses for, the artist, allowing themselves to be viewed. 5 Broadly speaking, a 'self-portrait' is an image constructed of oneself by oneself. In this sense, it offers a 'first-person' rendering, in contrast to a portrait's 'third person' perspective.6 Many dance works pose generative questions when thought about in relation to the traditions of portraits and self-portraits. For instance, is a selfauthored work necessarily a self-portrait of the artist? Does the dancing body always reveal or express something of the inner life of the mover? Furthermore, some works problematize these two categories because the choreographer and dancer (in cases where they are different people) both contribute to the construction of meaning. An artist might choreograph a work about themselves, which is then performed by other dancers, or else she might make a work 'on' particular dancers, using their unique movement styles and material contributed by the dancers, thus both parties contribute to the expression of the work.

Tomić-Vajagić discusses ways that performance 'blends' first and third person perspectives.7 Writing initially about visual art, she suggests that "some self/portraits as sites of performance may produce interesting destabilizations of the work and imply equivocal meanings due to the amplified blending of the inside and outside points of view." 8 Tomić-Vajagić goes on to argue that dance performances have the 
potential to produce similarly "ambivalent self-presentations," 9 which she terms "self/portrait effects." 10

52 Portraits and Vis-er-al both generate self/portrait effects. For example, each of the micro-works in 52 Portraits is created through the combined contribution of the featured artist, Burrows, Fargion, and Glendinnig, meaning that the portrayal combines internal and external viewpoints. Vis-er-al also blends "inside and outside points of view." Hudson choreographed the movement, and worked with Matthew Beckett to film and edit the work. Furthermore, the camera-work means that the work fluctuates between direct comprehensible images of Hudson's face and body, and more abstract images. While self-portraits in the visual art tradition might also work with abstraction, the temporality of film means that it is possible to fluctuate between abstract and direct representations, blending representational views.

\section{Portraits}

52 Portraits is a year-long work, sent via email to subscribers in weekly installments and archived on the work's website. The entire series was also screened at Sadler's Wells in London (UK) in January 2017. Most of the featured artists are UK-based, although there are some European and American artists included. The series draws on practices outside of, or on the edge of, contemporary dance, and features artists at various stages of their career. The majority of the portraits are solos, although there are some duets, and one group piece (the final portrait, which is of the artistic team: Burrows, Matteo and Francesca Fargion, and Glendinning). The framing is very simple. The artists sit at, on, next to, or above, a table in a black box space. Off-screen Fargion and/or his daughter Francesca sings a song constructed of stories and anecdotes from the featured artists' lives. The artists perform a series of movements, which tend towards the gestural, inasmuch as they do not entail large, whole-body movements or travel in space. However, despite these commonalities, each installment is unique. The choices the artists make within the set frame of the work reveal aspects of their approach to movement. As dance critic Judith Mackrell writes of 52 Portraits, "It's often in the tiny variables, within each snapshot, that the most penetrating information is revealed." 11

The first portrait in the series is of Kwame Asafo-Adeji, Artistic Director of the contemporary hip-hop company Spoken Movement. Asafo-Adeji performs staccato, syncopated hand-gestures on the table in front of him. At times his movements extend into space, but they remain within a small kinesphere that does not reach beyond the table and chair. He starts with his head bowed low to the table. It rises suddenly as he grasps the space in front of him. His gaze follows his hands, only occasionally meeting the camera, giving the portrait an inward tone. While AsafoAdeji moves, Matteo Fargion sings, recounting stories from the artist's childhood, such as falling from a coconut tree at age five. Fargion describes Asafo-Adeji's early 
movement inspiration (Michael Jackson), and his mother's job as a midwife, explaining in the final line of the song that she will soon retire back to her house in Ghana.12

At one point Fargion sings, "Kwame says that when he dances it doesn't feel like he's there at all." ${ }_{13}$ This description of the artists' internal world parallels with his inward gaze. While his movement material is sharp, fast, and energetically present; the tone of Asafo-Adeji's focus tells a different story. He appears contemplative, absorbed. The lyrics highlight the potential of dancing to offer a place where the artist can disappear, demonstrating how the portrait offers a collision of his internal and external worlds. His body is present; but his sensation is of disappearance-a tension evident in the relationship between his hand gestures and gaze.

The portrait from Scottish dance artist Claire Cunningham also starts with the artist looking down at the table. Like Asafo-Adeji, and most of the other artists, she is seated behind the table, square to the camera. Piano music starts before she moves. She slowly lifts her hands, which have been resting on the table in front of her. The movements are small at first, her fingers move as if playing a piano. As the movement grows larger, Cunningham starts to rock, and we see that she is sitting on a pair of crutches. For those familiar with Cunningham's work this does not come as a surprise, yet the structure and framing of this opening draws attention to the crutches, through their initial invisibility. This time it is Francesca Fargion who sings. "Claire is concerned with the notion that disability is a valid and positive way of existence." 14 She goes on to describe Cunningham's feelings about dancing, as "like curiosity or like physics" and "quite mechanical." ${ }_{15}$ Cunningham's gestural movements start to grow larger; her hand and arm extending further across the table, to draw her body round to face the back of the set. She moves slowly; the momentum created by the interplay between her movement and the balance of her body on her crutches creates a gentle, lilting dynamic. As Cunningham explores different balances, new shapes are revealed through the configuration of her body and crutches. Simultaneously, Fargion describes how the artist never quite knows what will happen next, drawing attention to the unpredictability of the movement. Towards the end of the portrait Cunningham leaves her crutches, moves into a deep plié, and walks to the side of the table. To exit the space, Cunningham pushes herself from the edge of the table and stands next to it, as the crutches balance on the rear edge. As with Asafo-Adeji's portrait, the interplay between the text and the movement, and subsequent merging of internal experiences and external movement presents a different picture of the artists than would be evident in the movement alone. However, the text does not describe the movement directly, but at times, highlights certain facets of it.

My consideration of 52 Portraits relates to Tomić-Vajagić discussion of Rineke Dijkstra's time-based portraits of young people club dancing. Analyzing Dijkstra's 2009 video installation The Krazyhouse, Tomić-Vajagić explains how the work follows a set format, with each performance taking place in a studio against a white backdrop, but that the 
dancers selected their own music and were free to move however they pleased.16 Tomić-Vajagić suggests that some of the dancers generate the self/portrait effect through the self-expression evident in their movement.17 Additionally, the interplay between Dijkstra's setting, structure, and instruction, and the decisions of the dancers can generate a self/portrait effect, through the blending of first and third person perspectives, which produce a 'liminal' space between perspectives. 18

I suggest that consideration of the self/portrait effect can function as an analytic tool, drawing us into deeper interrogation of the layers of representation generated in (screen)dance. As Tomić-Vajagić points out, "Any depictions of people or performances arguably may involve a certain blending of the first- and third-person perspectives." ${ }_{19}$ However, she goes on to point out that there are certain works in which the blending of perspectives is 'amplified.' 20 I suggest 52 Portraits is a clear example of this amplification. The work uses a similar structural device to Dijkstra's portraits. In this case, Burrows, Fargion, and Glendinnig determine the sound, camera work, and staging. Burrows also offers movement structures. For example, in an email to contributing artists Igor and Moreno, published in the program for the live screening, 21 and available on the website, Burrrows explains how he offers artists the structure from a classical music form called La Folia (a triple meter tune played in a minor key, which Burrows describes as having a "looping structure" made up of four phrases).22 He also offers other structures, and artists can choose whether or not to work with them. As well as selecting a structure, the featured artist(s) generate(s) the movement content. Therefore, there is openness within the set parameters of the work, which cultivates an effect akin to Tomić-Vajagić's blending of internal and external perspectives.

Furthermore, ambiguity is generated by the multiple authorial contributions and subsequent dialogue between the text and the movement. Many of the portraits are accompanied by a song about the artist's experiences and beliefs. The text arises from interviews between Burrows and the artists.23 Parts of the responses are then selected by Burrows and made into a song by Fargion.24 The result is that the words of the artists are re-told through the song, demonstrating a blending of perspectives. Furthermore, the relationship between the movement and the sound is not transparent. As demonstrated in the descriptions of Asafo-Adeji' and Cunningham's portraits, at times the artists appear to be responding directly to the text, while other sections are more abstract. As viewers, we are left to wonder whose perspective formed the relationship between the movement and text. The question of when the artists' expression becomes Burrows' and vice versa reveals the 'liminal space' described by Tomić-Vajagić, 25 generating a self/portrait effect. 


\section{Vis-er-al}

Vis-er-al starts with a shot of Polly Hudsons's inverted body. Clothed in a white dress, her pelvis points upwards, her back is visible, but her head, shoulders and neck are hidden. She appears to be in a shoulder-stand, but is in fact filmed from above, with her head hanging over her legs. It is hard to tell this at first, partly due to her suspension in the weightless space of the black screen. With nothing to indicate a floor, ceiling or walls, the body floats. Her back and pelvis form an abstract, mushroom-like shape, which is not immediately recognizable as a body.

Alongside the minimal, electric sound-score by Darren Pickles, Hudson's body unfolds, her head lifting towards the camera. The film is shot on a FS700 camera and therefore the movement unfolds in in slow motion. The momentum of Hudson's long hair implies a sense of haste that does not match the speed of the film. Her hair fills the screen, but just before her face appears beneath it, the camera switches perspectives. This time the shot is very close to Hudson's chest. Her shoulders, clavicles, and the top of her breasts fill the screen, but her face remains out of view. Still in slow motion, we see her chest rise with an intake of breath and fall with an exhale. This is accompanied by a rhythmic, gong-like sound, which adds a sense of weight to her movement. The camera cuts again to her lips and nose before moving above her body. A zoomed-out perspective allows us to see her full body in a less abstract form: as she moves slowly with her arms out in front of her, the camera rotates around her body, generating a sense of momentum.

Those who experience this work at a screening are likely to read the accompanying program note that explains how the work arose from Hudson's experience of being in a car accident.26 The relationship between the camera, the movement, and the music generate a sense of foreboding or trauma. The short, fragmented shots, deepbreathing, and off-balance camera-work all contribute to a sense that Hudson is experiencing something upsetting. At 1 minute 10 seconds, Hudson's face is fully revealed. The camera then moves to a birds-eye view, maintaining the sense of momentum - perhaps arising from impact-and we see Hudson's body mid-flow. The movement of her hair indicates speed and velocity, despite the slowness of the footage. As the film continues, these moments are interspersed with stillness and close-up images of Hudson's hands, chest, and neck. A prolonged shot features water falling through her hands. It is not evident to the viewer where the water originates from, or its significance in Hudson's story. Its movement becomes part of an eclectic vocabulary of images, shot from multiple perspectives and generating ambiguous forms of expression.

This example does not offer the same relationship between set structure and openness as the previous example, but it can be said to extend the self/portrait effect seen with 52 Portraits above. The autobiographical nature of the work means it could 
be interpreted as a straightforward self-portrait, however, the mediation of the camera, and central role of editing, means that a third person perspective is brought to bear on the movement, generating an interplay of perspectives similar to that described by Tomić-Vajagić. For example, the slow-motion effect, rotation of the camera, and the fast-paced editing combines with the movement to generate a sense of unease and trauma, thus Hudson's experience is portrayed through a combination of first and third person perspectives. Furthermore, the viewer is at times engaged with Hudson directly, through clear shots of her face and body. At other points, her body is abstracted. This movement between literal and abstract renderings combines with the mixed perspectives to generate a self/portrait effect. Considering this work in relation to this concept allows us to more clearly comprehend the multiple forms of (self)representation that take place in the work.

\section{Relationality}

In Portraits and Persons, Cynthia Freeland paraphrases Jerrold Siegel's suggestion that there three main dimensions of the self: the bodily (or material), the reflective, and the relational. Freeland remarks, "The bodily nature of the self involves its existence as a physical entity with particular sorts of needs and vulnerabilities, and a specific external appearance. The reflective aspect of the self involves its nature as being endowed with consciousness, capable of assessing and forming itself, shaping actions etc. The relational aspect of the self involves truths about people's membership in groups that impart values and roles." 27 Dance works might appear to present the bodily or material self, manifested in screendance through mediated corporeality. However, I suggest that 52 Portraits and Vis-er-al demonstrate how the relational self 28 is also integral to these works.

Freeland suggests, "To say the self is constituted by various relationships may seem rather obvious, but specifying how such a view can be artistically rendered is harder." 29 52 Portraits and Vis-er-al demonstrate how (screen)dance provides fertile ground for rendering the relational self. For instance, in the case of 52 Portraits, the micro/macro work structure shows how the artists featured are part of a larger picture (or group). Although they are individual artists (or artistic partnerships), they are also members of something bigger than themselves. Members of the group might disagree about specific values, ideas, or movement concerns, but watching the pieces back-to-back, 30 it appears that there are sufficient overlapping values between members of the group to generate a network or 'community' of practitioners who are in relation to one another, even if this relation is indirect. The relations between the artists are constructed from the third-person perspective. Contextualization is provided through the team's curation and framing. As viewers, our engagement with each artist's portrait and consideration of the way their selfhood is communicated happens in relation to the other portraits within the work. Thus, the third-person rendering of the relational self, informs our reading of the artist's (self)representation, further 
complicating the interplay between first and third person perspectives and contributing to the self/portrait effect.

In the case of Hudson's work, the relational self is generated through the context within which it is shown. It is screened at festivals dedicated to screendance as well as at video art festivals and events. Being shared in these venues contextualizes Hudson's work as constructed in relation to other artists, emphasizing the place of the work within particular areas of practice. For example, relationality between Hudson and her contemporaries is demonstrated by her decision to place the work alongside other artists' practices, such as Katye Coe and Charlie Morrissey, as described in the opening section. Furthermore, in the case of the 9 Evenings event, the work was contextualized in relation to avant-garde performance practices in the 1960s. This arose through Hudson's reference to Yvonne Rainer's "No Manifesto," and the wider context of the 9 Evenings event, initiated by Vivid Projects. The combination of Hudson's curatorial choices, and the broader framework of the series further demonstrates the multiple perspectives that contribute to the work's contextualization, and its positioning in relation to historical and current practices.

In each example, the artist expresses themselves, mediated via a third person perspective and in relation to others. Thus, self-expression is one component of a larger network of expressive, aesthetic factors. Recognizing that (self)representation is partly concerned with the relational self in these examples helps us to further reveal their layers of representation and composition. Freeland suggests that in visual art, rendering the reflective and relational aspects of self has always been a challenge, in comparison to the relatively straightforward depiction of the material body.31 In dance, while the material body is central to the form, the relational self might also manifest, even in solo works, through the contexts of their transmission. Furthermore, we might want to argue that the muddling of perspectives evident in these works starts to erode the distinction between the material and relational self, implying our material corporality arises in relation to others, and is constructed through a confluence of internal and external perspectives.

Examining 52 Portraits and Vis-er-al in relation to the visual art convention of portraits and self-portraits shows how contemporary (screen)dance practices cultivate ambivalent forms of (self) representation through the blending of multiple authorial and mediatized perspectives, resulting in self/portrait effects. This brief study raises multiple questions, such as: How might further examination of this area reveal the interplay between movement, choreography, and self-expression? How might screendance practices undo, disrupt, or complicate thinking in visual art about (self) expression and representation? And how might different forms of circulation and transmission extend and transform the relational self? I leave these questions here as a way to stimulate thinking about some of the complex forms of (self)expression that screendance can generate. 


\section{Biography}

Dr Hetty Blades is a Postdoctoral Research Assistant in the Centre for Dance Research (C-DaRE) at Coventry University. Her research considers the philosophical questions posed by dance practices in both live and mediatized spaces. Hetty is published in Performance Philosophy Journal (2017, 2016), Performance Research (2015) and Choreographic Practices (2015). Hetty is Editorial Assistant for Journal of Dance and Somatic Practices. She was Researcher in Residence at the Digital Catapult in 2016.

Email:ac1417@coventry.ac.uk

\section{Notes}

1 Tamara Tomić-Vajagić, "The Self/portrait Effects and Dance Performance," 82.

2 I borrow this construct from Tomić-Vajagić.

3 Yvonne Rainer, "Some Retrospective Notes."

4 According to Cynthia Freeland, portraits can also be of animals. See Portraits and Persons.

5 Idem, 21.

6Tomić-Vajagić, 82.

7 lbid.

8 lbid.

9 Idem, 81.

10 Idem, 82.

11 Judith Mackrell, "52 Portraits," n.p.

12 "Kwame Asafo-Adeji," 52 Portraits, Dir. Jonathan Burrows, et al.

13 lbid.

14 "Claire Cunningham," 52 Portraits.

15 lbid.

${ }_{16}$ Tomić-Vajagić, 82.

17 Tomić-Vajagić provides a detailed analysis of how the self/portrait effect is generated in some of Dijkstra's portraits, suggesting that is is particularly present in three out of five, 86.

18 Tomić-Vajagić, 82.

19 lbid.

20 Idem, 83.

${ }_{21}$ Burrows et al, 52 Portraits program.

22 Ibid.

23 Ibid.

24 lbid. 
25 Tomić-Vajagić, 82

${ }_{26}$ Burrows et al, 52 Portraits program.

${ }_{27}$ Freeland, Portraits and Persons, 81-81.

28 Here I follow Freeland's use of the term to describe "the self in its various social relations and public roles" (97). The term is also used to refer to the self as it is constructed through relationships with people we are close to such family and friends. 29 Idem, 98.

30 As I did during a screening at Sadler's Wells on 25 January 2016.

${ }_{31}$ Freeland, 83.

\section{References}

52 Portraits. Dir. Jonathan Burrows, Matteo Fargion, Hugo Glendinnig, and Claire Cunningham. UK, 2016. Sadler's Wells. http://52portraits.co.uk/

Burrows, Jonathan, Matteo Fargion, and Hugo Glendinning. 52 Portraits. Program Note. 2017.

"Claire Cunningham," 52 Portraits. Dir. Jonathan Burrows, Matteo Fargion, Hugo Glendinnig and Claire Cunningham. UK, 2016. Sadler's Wells.

http://52portraits.co.uk/home/2016/5/2/claire-cunningham

Freeland, Cynthia. Portraits and Persons. London and New York: Oxford University Press. 2010.

"Kwame Asafo-Adeji," 52 Portraits. Dir. Jonathan Burrows, Matteo Fargion, Hugo Glendinnig and Kawme Asofo-Adeji. UK, 2016. Sadler's Wells.

http://52portraits.co.uk/home/2015/12/18/kwame-asafo-adjei

Mackrell, Judith. "52 Portraits: a year of solos capturing dancers' fears and freedom." The Guardian. 09 August 2016. https://www.theguardian.com/stage/danceblog/2016/aug/09/52-portraits-dancers

Making Lemonade. Dir. Polly Hudson. Camera Rebecca Pittam. Composer Darren Pickles. Lighting Catherine Cullinane UK, 2016.

Rainer, Yvonne. "Some Retrospective Notes on a Dance for 10 People and 12 Mattresses Called 'Parts of Some Sextets,' Performed at the Wadsworth Atheneum, Hartford, Connecticut, and Judson Memorial Church, New York, in March, 1965." The Tulane Drama Review 10.2 (1965): 168-178. https://doi.org/10.2307/1125242 
Tomić-Vajagić, Tamara. "The Self/portrait Effects and Dance Performance: Rineke Dijkstra's The Krazyhouse and William Forsythe's the second detail." Performance Research 19.5 (2014): 82-92. https://doi.org/10.1080/13528165.2014.958362

Vis-er-al. Dir. Polly Hudson. Director of Photography Matthew Beckett. Composer Darren Pickles. UK, 2016. 